\title{
NOTE
}

\section{Feeding of captive, tropical carcharhinid sharks from the Embley River estuary, northern Australia}

\author{
J. P. Salini ${ }^{1, *}$, M. Tonks ${ }^{2}$, S. J. M. Blaber ${ }^{1}$, J. Ross ${ }^{3}$ \\ ${ }^{1}$ CSIRO Division of Marine Research, PO Box 120, Cleveland, Queensland 4163, Australia \\ ${ }^{2}$ Southern Fisheries Centre, QDPI, Deception Bay, Queensland 4508, Australia \\ ${ }^{3}$ Environmental Protection Agency, Brisbane 4000, Australia
}

\begin{abstract}
Twenty carcharhinid sharks of 3 species were fed pilchards at different frequencies to examine feedinggrowth relationships. These results are among the first in Australia on food intake and growth of wild-caught juvenile and sub-adult carcharhinids held in captivity. Mean consumption rates $( \pm$ SE) for all feeding rations were $2.91 \%$ $( \pm 0.28)$ body weight per day (BWD) for Carcharhinus dussumieri, $3.44 \%( \pm 0.40)$ BWD for C. tilstoni and $3.35 \%( \pm 0.34)$ BWD for Negaprion acutidens. $N$. acutidens had the highest consumption rate of $5.02 \%$ BWD at 2 feeds $\mathrm{d}^{-1}$ Highest mean growth rates were $0.78 \%( \pm 0.11) \mathrm{BWD}$ for $C$. dussumieri, $1.34 \%$ BWD $( \pm 0.54)$ for $C$. tilstoni and $1.12 \%(\mathrm{n}=1) \mathrm{BWD}$ for $N$ acutidens. Maintenance ration estimates were $1.29 \%$ BWD for C. dussumieri, $1.31 \%$ BWD for $N$. acutidens, and $2.06 \% \mathrm{BWD}$ for $C$. tilstoni. These are similar to literature estimates. High consumption rates did not always translate directly to high growth rates.
\end{abstract}

KEY WORDS: Sharks Consumption - Growth · Feeding · Carcharhinus Negaprion

The carcharhinid sharks of tropical Australia are major predators of commercially important penaeid prawns (Brewer et al. 1991, 1995, Salini et al. 1990. 1992). Four species - Rhizoprionodon acutus (Rüppell 1837), Carcharhinus dussumieri (Valenciennes 1839), C. amblyrhynchos (Bleeker 1856) and Himantura toshi (Whitley 1939) - are abundant in the prawn fishing grounds of Albatross Bay (northeastern Gulf of Carpentaria) and account for over $40 \%$ of the predation on commercial penaeids (Brewer et al. 1991). These predation estimates were arrived at by using species abundances ( $\left.\mathrm{kg} \mathrm{ha}^{-1}\right)$, proportion of prawns in the diets and a conservative daily ration value of $3 \%$ body weight per day (BWD) for all fish predators.

This daily ration value was derived from literature values for teleosts. It was followed by a series of

•E-mail: john.salini@marine.csiro.au experiments on the main teleost penaeid predators in order to obtain realistic estimates of their daily consumption rates (Smith et al. 1991, 1992). The present study was aimed at confirming the consumption rate used for sharks in calculating levels of predation on prawns.

Few direct measures of shark consumption and growth have been reported. Cortés \& Gruber (1994) have studied the effect of ration size on growth of the lemon shark Negaprion brevirostris a species closely related to $N$. acutidens used in our study. Medved (1985) studied gastric evacuation in the sandbar shark Carcharhinus plumbeus by feeding them known quantities of food and then sacrificing the sharks at intervals

Materials and methods. Seawater system: Experiments were carried out at the CSIRO Marine Laboratories field station at Weipa (northeastern Gulf of Carpentaria, Australia) using 4 above-ground pools, $3.7 \mathrm{~m}$ diameter, $7000 \mathrm{l}$, under cover of double-layered, $95 \%$-shading shade cloth and open to the environment. Seawater was fully exchanged every $2 \mathrm{~d}$ using water from the Embley estuary about $100 \mathrm{~m}$ away. Water was filtered through a domestic pool sand filter and water temperature and salinity were recorded daily, Nitrites and pH levels were monitored every $5 \mathrm{~d}$ during experiments and rarely differed by more than $10 \%$. An ambient light regime was used.

Capture of sharks: All sharks were caught in waters near the field station using 2 longlines of up to 20 hooks each. Baited lines were checked hourly as sharks were quickly exhausted or stressed beyond recovery after only 10 to $20 \mathrm{~min}$ on the hook. Most sharks settled down to a stable swimming pattern within minutes of revival in the pools and accepted food within a few days of capture. They were used in experiments $1 \mathrm{wk}$ after regular feeding commenced. 
Feeding experiments: Consumption and growth experiments lasted $10 \mathrm{~d}$ with weight and total length recorded before and $24 \mathrm{~h}$ after the experiments ceased. Sharks were not fed for $24 \mathrm{~h}$ before weighing and measuring. They were anaesthetized in a 251 bath of 100 ppm MS-222 until motionless, quickly carried in the 'tonic immobility' posture (Gruber \& Keyes 1981) to be weighed ( $\pm 1 \mathrm{~g}$ ) and measured (total length) to the nearest millimetre. No shark died as a consequence of anaesthesia during the experiments. Ten Carcharhinus dussumieri (664 to $780 \mathrm{~mm} \mathrm{TL}, 1350$ to $2170 \mathrm{~g}$ ) were used in 12 experiments; 4 Negaprion acutidens ( 652 to $864 \mathrm{~mm}$ TL, 1250 to $1350 \mathrm{~g}$ ) in 10 feeding experiments; and 4 Carcharhinus tilstoni $(609$ to $721 \mathrm{~mm} \mathrm{SL}$, 1150 to $2290 \mathrm{~g}$ ) were used for 8 experiments.

The following feeding frequencies were used during the experiments:

(1) 2 meals $\mathrm{d}^{-1}$ (feeding frequency $=2.0$ ); (2) 1 meal $\mathrm{d}^{-1}(1.0)_{i}$ (3) 1 meal every $2 \mathrm{~d}(0.5)_{i}$ (4) 1 meal every $3 \mathrm{~d}(0.33)$; (5) zero meals over $5 \mathrm{~d}(0) ;(6) 25$ meals over $20 \mathrm{~d}$ (1.25).

Sharks were fed to satiation with pre-weighed, bitesized portions (to prevent shredding) of frozen pilchards (Sardinops neopilchardus Steindachner), excluding viscera and heads, at each feeding. Daytime meals were between 08:00 and 09:00 h and, for those fed twice a day, between 16:00 and 17:00 $h$; all uneaten food was removed and weighed after $5 \mathrm{~min}$. This allowed the calculation of food consumed for each feeding period.

Data analysis: The growth increment $(G)$, expressed as a percentage of body weight $\mathrm{d}^{-1}$ (\% BWD) was calculated as the difference between pre- and post-experiment weights and was calculated from the formula

$$
G=100\left(W_{N}-W_{0}\right) / N W_{0}
$$

where $W_{0}$ is the mean shark weight on day $0, W_{N}$ is the mean shark weight (to account for variability between individuals) at the end of each experiment and $N$ is the duration of the experiment, that is $10 \mathrm{~d}$ for feeding and 5 d for starvation experiments (Smith et al. 1991). Consumption rate $\left(C\right.$, or the $\%$ body weight eaten $\mathrm{d}^{-1}$. $\%$ BWD) was calculated from the formula

$$
C=100 C_{t} / N_{n}\left(W_{N}+W_{0}\right) / 2
$$

where $C_{t}$ is the total food ingested by all sharks in the experiment, $n$ is the number of sharks and $\left(W_{N}+W_{0}\right) / 2$ is the mean shark weight (Smith et al. 1991).

Growth was regressed against consumption; a linear relationship of the form

$$
G=g+h C
$$

provided the best fit for each species. Parameters $g$ and $h$ represent starvation weight loss (resting metabolic rate when $C=0$ obtained during the $5 \mathrm{~d}$ starva- tion experiments) and the slope of the line of best fit (or rate of change in growth with change in consumption respectively. Maintenance ration $(G=0)$ can be estimated using the above parameters from the least squares linear regression for Growth versus Consumption.

Results. Physical environment: Salinity varied between 19.0 and 32.0 parts per thousand (ppt) during the experiments due to seasonal rainfall. There was no apparent distress or change in behaviour of the sharks when in the lower salinities, probably because they are adapted to similar regular salinity changes in the estuary. Temperature was less variable with a range of 26.2 to $30.0^{\circ} \mathrm{C}$, made up of about a $2^{\circ} \mathrm{C}$ diurnal variation and about a $2^{\circ} \mathrm{C}$ seasonal change in temperature of the incoming seawater over $4 \mathrm{mo}$
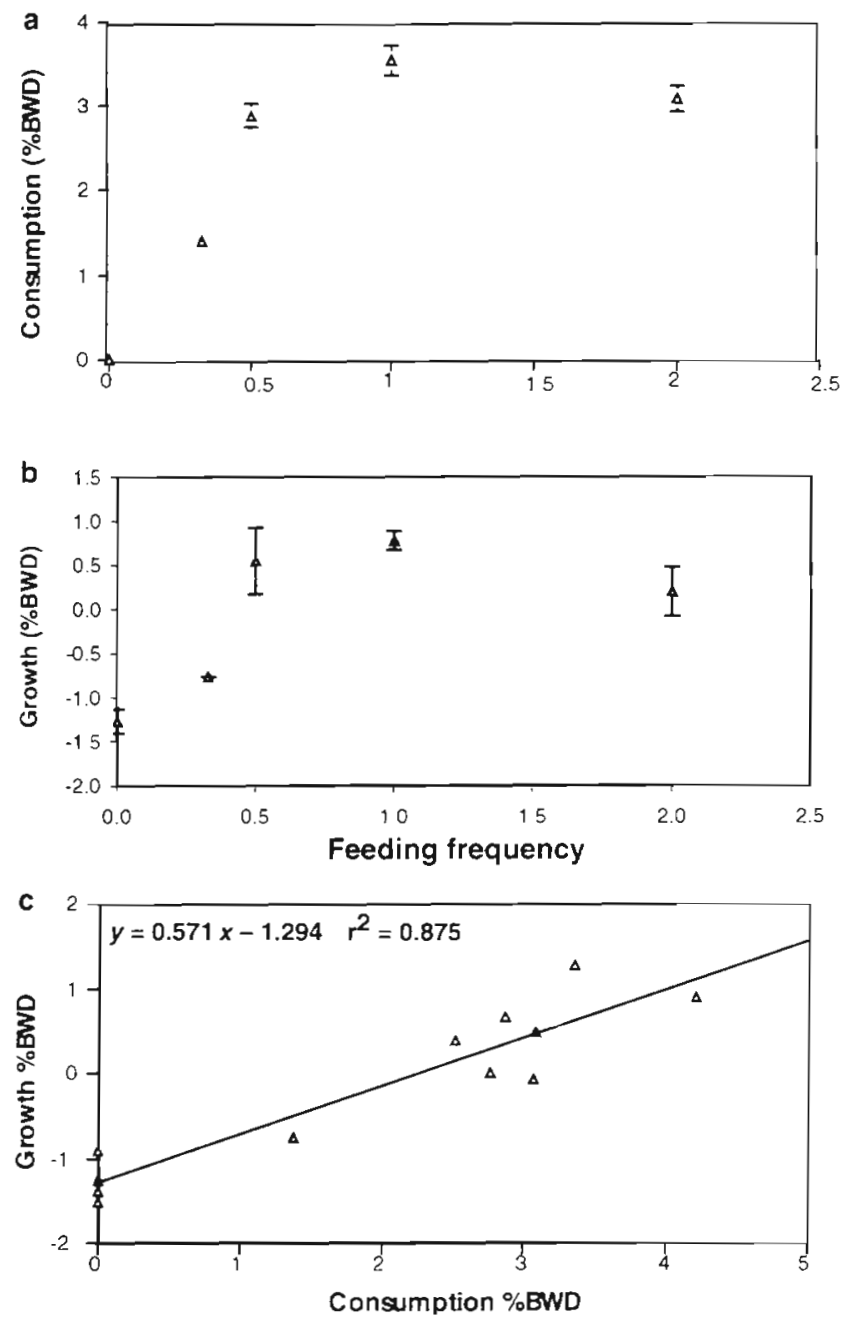

Fig. 1. Carcharhinus dussumieri. The relationship between feeding frequency (no. of meals $d^{-1}$ ) and (a) consumption rate, (b) growth rate and (c) consumption regressed against growth. Consumption and growth rates are expressed as percentage of body weight $\mathrm{d}^{-1}(\% \mathrm{BWD})$ 

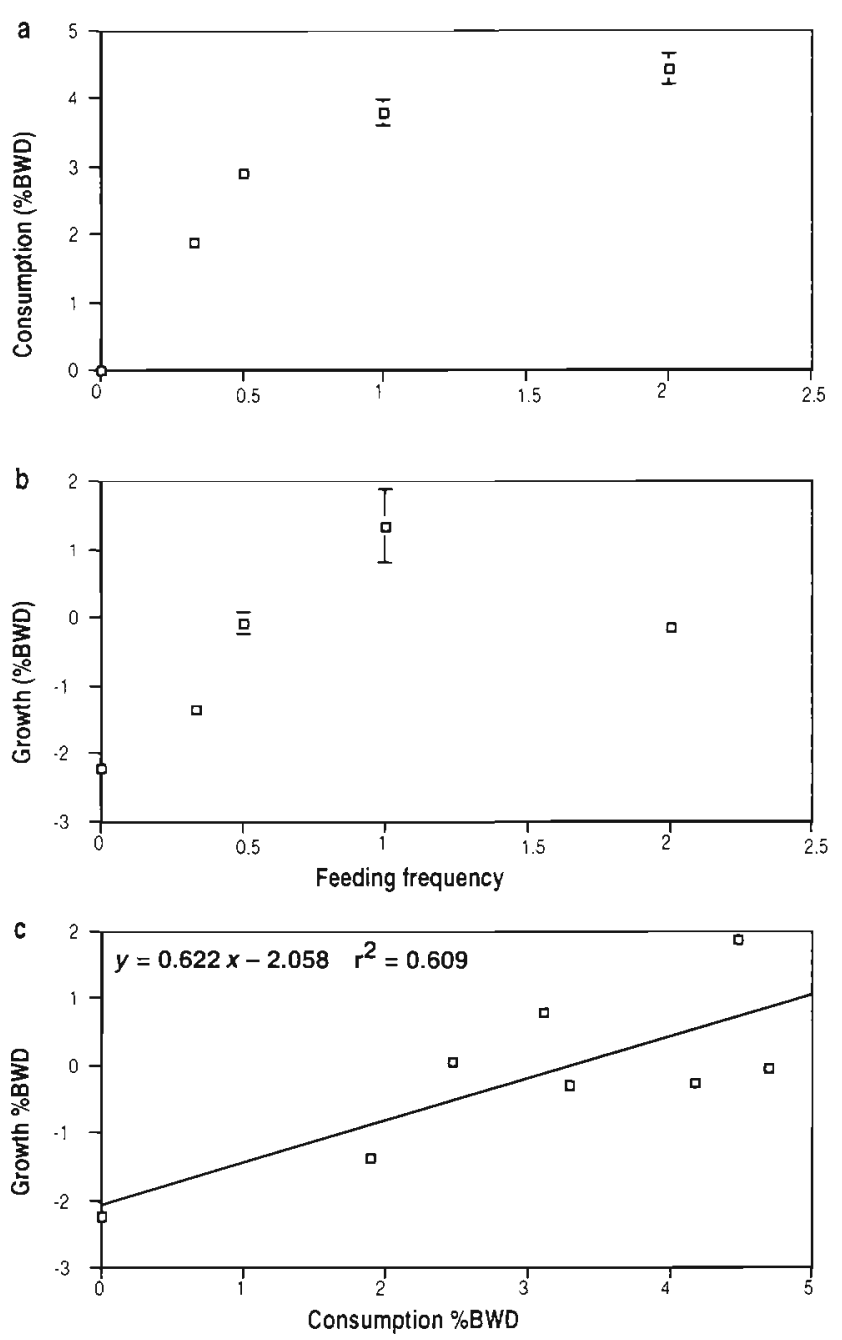

Fig. 2. Carcharhinus tilstoni. The relationship between feeding frequency (no. of meals $\mathrm{d}^{-1}$ ) and (a) consumption rate, (b) growth rate and (c) consumption regressed against growth. Consumption and growth rates are expressed as percentage of body weight $\mathrm{d}^{-1}(\% \mathrm{BWD})$

Experiments: Carcharhinus dussumieri: Average consumption $( \pm \mathrm{SE}$ ) of pilchards by $C$. dussumieri was highest when the feeding frequency was once $\mathrm{d}^{-1}$ $(3.5 \% \mathrm{BWD} \pm 0.66)$, and second highest when it was twice $d^{-1}(3.1 \%$ BWD \pm 0.01 , Fig, 1a). Growth $( \pm S E)$ showed a similar trend with a maximum value of around $0.8 \%$ BWD $( \pm 0.11)$ when fed once $\mathrm{d}^{-1}$, but feeding once every $2 \mathrm{~d}$ still gave a growth of $0.6 \%$ BWD ( \pm 0.38 ) (Fig. 1b). Despite the levelling off of consumption and growth with increased meal frequency, there was a strong correlation between growth and consumption (Fig. 1c, r = 0.94, $p<0.001$ ).

Carcharhinus tilstoni: Consumption $( \pm \mathrm{SE})$ of pilchard by $C$. tilstoni was highest for 2 feeds $\mathrm{d}^{-1}$ (average of 2 experiments, $4.4 \%$ BWD \pm 0.26 ), with slightly lower consumption for 1 feed $\mathrm{d}^{-1}$ (average of 2 experiments, $3.8 \%$ BWD \pm 0.69 , Fig. 2a). Growth $( \pm \mathrm{SE})$ was highest for 1 feed $\mathrm{d}^{-1}$ (average of 2 experiments, $1.3 \% \mathrm{BWD} \pm 0.53 \mathrm{k}$. In contrast, the maximum feeding ration of 2 times $\mathrm{d}^{-1}$ produced an average weight loss of $-0.2 \%$ BWD \pm 0.12 ), suggesting disrupted digestion with little or no assimilation of the consumed pilchard (Fig. 2b). The correlation between growth and consumption is significant but had higher variability between replicate experiments than $C$. dussumieri (Fig. 2c, $r=0.78, p<0.01$ ).

Negaprion acutidens: Consumption rate was highest (5.0\% BWD, single experiment only, Fig. 3a) when fed twice $\mathrm{d}^{-1}$ but was consistently relatively high even at 1 feed $3 \mathrm{~d}^{-1}$. The highest growth rate was $1.1 \%$ BWD for the 1.25 feeds $\mathrm{d}^{-1}$ (25 feeds during a single $20 \mathrm{~d}$ experiment, Fig. $3 \mathrm{~b}$ ). The highest consumption rate did
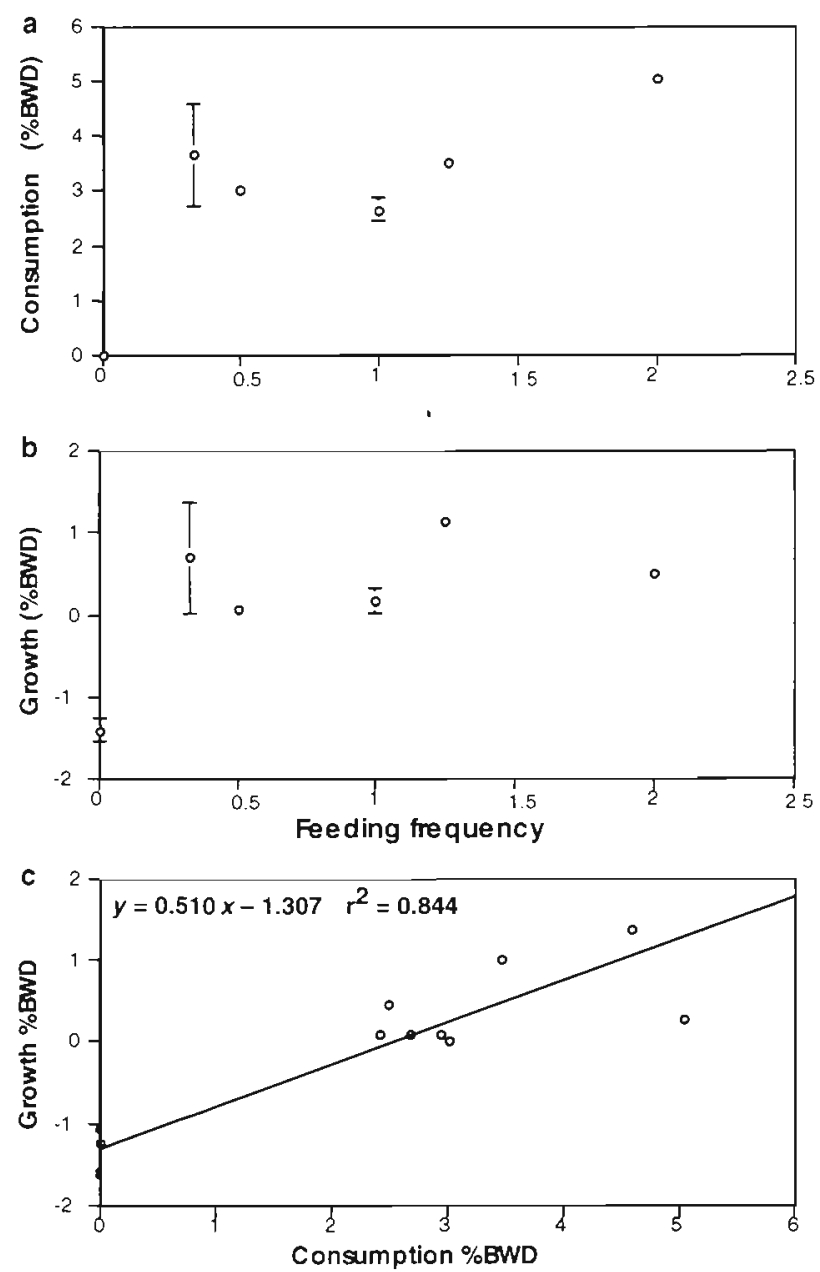

Fig. 3. Negaprion acutidens. The relationship between feeding frequency (no. of meals $\mathrm{d}^{-1}$ ) and (a) consumption rate, (b) growth rate and (c) consumption regressed against growth. Consumption and growth rates are expressed as percentage of body weight $\mathrm{d}^{-1}$ (\%BWD) 

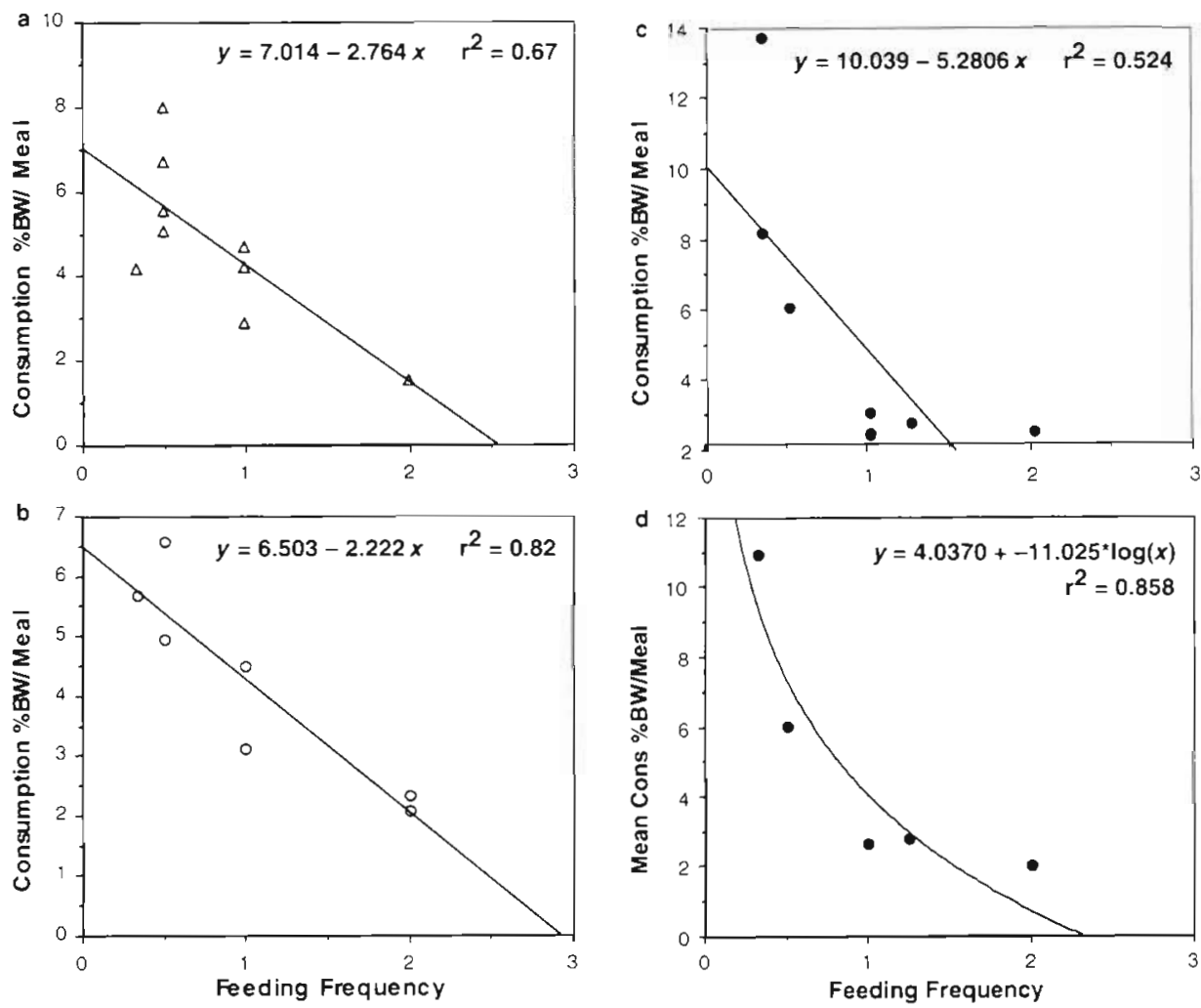

Fig. 4. The linear relationship between meal size (as $\% \mathrm{BW}$ meal ${ }^{-1}$ ) and feeding frequency expressed as meals $\mathrm{d}^{-1}$ for (a) Carcharhinus dussumieri. (b) Carcharhinus tilstoni, (c) Negaprion acutidens, and (d) the logarithmic relationship between meal size and feeding frequency for Negaprion acutidens

not produce the highest growth rate although there was a strong relationship between consumption and growth (Fig. 3c, r =0.92, p <0.001).

Comparison between species: Average consumption rates $( \pm \mathrm{SE}$ ) for all feeding frequencies were $2.9 \%$ $( \pm 0.28)$ BWD for Carcharhinus dussumieri, $3.4 \%$ $( \pm 0.40)$ BWD for C. tilstoni and $3.4 \%( \pm 0.34)$ BWD for Negaprion acutidens (Table 1). Maximum growth rate (mean) was $0.8 \%$ BWD $( \pm 0.11)$ for $C$. dussumieri fed once $\mathrm{d}^{-1}$ and was the product of the highest mean consumption rate, $3.5 \%$ BWD $( \pm 0.66) ; 1.3 \%$ BWD $( \pm 0.54)$ for $C$. tilstoni fed daily, and $1.1 \%$ BWD (no replicate) for $N$. acutidens fed 4 d out of 5 .

Values for starvation weight loss for Carcharhinus dussumieri, C. tilstoni and Negaprion acutidens were $1.3,2.1$ and $1.3 \%$ respectively. Maintenance ration at zero growth for $C$. dussumieri, $C$. tilstoni and $N$. acutidens was $2.3,3.3$ and $2.6 \%$ BWD respectively and was derived from the least squares linear regressions in Figs. 1c, 2c \& 3c.

Compensatory feeding behaviour: Carcharhinus dussumieri showed some compensatory feeding ability due to reduced feeding frequency (Fig. 4a), to a maximum of about $7 \% \mathrm{BW}$ meal $^{-1}$ (the $y$-intercept of the plot of single meal size as a percentage of body weight against ration). The single experiment for 1 meal every $3 \mathrm{~d}$ appears not to fit the trend (at $\sim 4.1 \% \mathrm{BW} \mathrm{meal}^{-1}$ ) of increasingly larger meals with less frequent feeding.
C. tilstoni adjusts its food intake up to about $6.5 \%$ BWD (Fig. 4b) by increasing meal sizes for less frequent meals. Negaprion acutidens has the most developed compensatory feeding behaviour of all 3 species (Fig. 4c). The maximum meal size occurs for the least frequent feeding experiments (once every $3 d$, $y$-intercept $10 \% \mathrm{BW}_{\text {meal }}{ }^{-1}$ ). The relationship is not linear. A log relationship provides a more accurate fit of the data, but allows unrealistic meal sizes near starvation (Fig. 4d).

Discussion. The tropical sharks in this study had consumption rates that were below those reported for juvenile tropical teleosts (Smith et al. 1991, 1992), but above those reported for temperate sharks (Medved et al. 1988). Other studies have also reported that elasmobranchs generally have lower rates of consumption than teleosts (Wetherbee \& Gruber 1990, Wetherbee et al. 1990). Our consumption rates were 5 to $6 \%$ BWD lower than in juvenile teleosts under $200 \mathrm{~g}$ wt (Smith et al. 1991, 1992).

Our sharks were able to increase consumption as feeding frequency increased to 2 meals $\mathrm{d}^{-1}$ except for Carcharhinus dussumieri, which slightly decreased its consumption with 2 meals $\mathrm{d}^{-1}$ (Fig. 1b). The highest consumption rate recorded (Negaprion acutidens when fed twice $\mathrm{d}^{-1}$, resulted in a relatively low growth rate of $0.5 \%$ BWD (Fig. 3a,b,c). Average consumption rates for all feeding frequencies decreased with less 
Table 1. Summary of maintenance ration, growth and consumption estimates from studies on various captive shark and teleost species. Values for the current study are averages over all feeding frequencies with SE given in 'Results'

\begin{tabular}{|c|c|c|c|c|}
\hline Species & $\begin{array}{c}\text { Maintenance ration } \\
(\% \text { BWD })\end{array}$ & $\begin{array}{l}\text { Growth } \\
\text { (\% BWD) }\end{array}$ & $\begin{array}{l}\text { Consumption } \\
(\% \text { BWD })\end{array}$ & Source \\
\hline Carcharhinus dussumieri & 1.2 & 0.8 & 2.9 & Present study \\
\hline C. tilstoni & 2.1 & 1.3 & 3.4 & Present study \\
\hline Negaprion acutidens & 1.3 & 1.1 & 3.4 & Present study \\
\hline N. brevirostris & & $-0.34-0.61$ & $0.6-2.73$ & Cortes \& Gruber (1994) \\
\hline N. brevirostris & & & $1.7-4.3$ & Wetherbee \& Gruber (1990) \\
\hline N. brevirostris & 1.6 & & & Gruber (cited in Medved et al. 1988) \\
\hline Carcharhinus plumbeus & & & 1.0 & Medved et al $(1985,1988)$ \\
\hline C. plumbeus & & & 0.86 & Stillwell \& Kohler (1993) \\
\hline Carcharias taurus & & & 0.27 & Schmid et al. (1990) \\
\hline C. plumbeus & & & 0.47 & Schmid et al. (1990) \\
\hline C. leucas & & & 0.5 & Schmid et al. (1990) \\
\hline Ginglymostoma cirratum & & & 0.31 & Schmid et al (1990) \\
\hline Caranx bucculentus & 2.7 & 1.3 & 8 & Smith et al. (1992) \\
\hline Lutjanus russelli & 3.8 & 1.1 & 9 & Smith et al. (1991) \\
\hline
\end{tabular}

frequent meals corresponding with a drop in growth, except in the case of $N$. acutidens which was able to consume larger meals infrequently (Fig. 4c,d). There was an obvious levelling off in daily consumption for each shark species with maximum values for individual replicates of $4.7 \%$ BWD for C. dussumieri, $4.7 \%$ BWD for $C$. tilstoni and $5.0 \%$ BWD for $N$. acutidens, although this limit was not tested with more than 2 meals $d^{-1}$. At 2 meals $d^{-1}$, all 3 species began to reject some of the second meal, hence no higher feeding frequencies were attempted. Variation in both consumption and growth within a feeding regime reflects the limited number of replicates attainable during the field work.

Few direct comparisons with other species are possible for tropical or subtropical sharks due to the paucity of published food intake and growth experiment results that are available. Consumption rates for a variety of carcharhinids reported in the literature ranged from 0.27 to $4.3 \%$ BWD (Table 1). The mean consumption rates demonstrated in the present study fall within this range of $2.1 \%$ BWD for Carcharhinus dussumieri, $3.4 \%$ BWD for C. tilstoni and 3.4\% BWD for Negaprion acutidens. Most studies derived consumption rate estimates from diet studies of wild sharks and empirical calcualtions (Medved et al. 1985, 1988, Stillwell \& Kohler 1993). C. plumbeus values were for adult sharks in commercial aquaria (Schmid et al. 1990).

Growth rates reported for Negaprion brevirostris ranged from -0.34 to $0.61 \%$ BWD under controlled conditions (Table 1). Our mean growth rate for N. acutidens was higher. Reported teleost growth rates were similar to those demonstrated for sharks in the present study, but the maintenance rations were about half those for juvenile Lutjanus russelli and juvenile
Caranx bucculentus (Smith et al. 1991, 1992, most fish were $<200 \mathrm{~g}$ ). Maintenance ration estimates for our sharks were comparable with those for $N$. brevirostris (Table 1). This supports the notion of sharks having generally lower energy requirements than teleosts (Gruber 1986, Wetherbee et al. 1990, Wetherbee \& Gruber 1993). The higher maintenance ration for Carcharhinus tilstoni is supported by our observations of high activity relative to the other sharks. Similarly, Hussain (1991) found that C. limbatus (closely related to $C$. tilstoni) swam faster than $N$. brevirostris in experiments at Sea World, Orlando, Florida.

Average meal size for Carcharhinus tilstoni and Negaprion acutidens increased with decreasing meal frequency to about $6.5 \% \mathrm{BW}$ for $C$. tilstoni and $13.5 \% \mathrm{BW}$ for $N$. acutidens. This is well above the $6 \% \mathrm{BW} \mathrm{meal}^{-1}$ limit found for the carangid C. bucculentus under similar experimental conditions (Smith et al. 1992) and suggests $N$. acutidens has considerable compensatory feeding ability.

Acknowledgements. Dr David Milton and Mr David Brewer (CSIRO Marine Laboratories, Cleveland) provided assistance in the field and commented on an early draft. Dr John Stevens (CSIRO Marine Laboratories, Hobart) provided advice on shark behaviour during the experiments.

\section{LITERATURE CITED}

Brewer DT, Blaber SJM, Salini JS (1991) Predation on penaeid prawns by fishes in Albatross Bay, Gulf of Carpentaria. Mar Biol 109:231-240

Brewer DT, Blaber SJM, Salini JS (1995) Feeding ecology of predatory fishes from Groote Eylandt, Australia, with special reference to predation on penaeid prawns. Estuar Coast Shelf Sci 40:577-600 
Cortés E, Gruber SH (1990) Diet, feeding habits and estimates of daily ration of young lemon sharks, Negaprion brevirostris (Poey). Copeia 1990(1):204-218

Cortés E, Gruber SH (1994) Effect of ration size on growth and gross conversion efficiency of young lemon sharks, Negaprion brevirostris. J Fish Biol 44(2):331-341

Gruber SH (1986) Bioenergetics of the lemon shark, Negaprion brevirostris (Poey) under laboratory and field conditions. Indo-Pacific-Fish Biology. In: Uyeno $T$, Arai $R$, Taniuchi T, Matsuura K (eds) Proc 2nd Int Conf Indo-Pacif Fish, Tokyo National Museum, Ueno Park, Tokyo, July 29-August 3, 1985

Gruber SH, Keyes RS (1981) Keeping of sharks for research. Aquarium systems. Academic Press, London, p 373-402

Hussain SM (1991) The behaviour of sharks in captivity. Indian J Fish 38(3):151-156

Medved RJ (1985) Gastric evacuation in the sandbar shark, Carcharhinus plumbeus. J Fish Biol 26(3):239-253

Medved RJ, Stillwell CE, Casey JG (1985) Stomach contents of young sandbar sharks, Carcharhinus plumbeus, in Chincoteague Bay, Virginia. Fish Bull 83(3):395-402

Medved RJ, Stillwell CE, Casey JG (1988) The rate of food consumption of young sandbar sharks (Carcharhinus plumbeus) in Chincoteague Bay, Virginia. Copeia 1988(4): $956-963$

Salini JP, Blaber SJM, Brewer DI (1990) Diets of piscivorous fishes in a tropical Australian estuary, with special reference to predation on penaeid prawns. Mar Biol 105: $363-374$

Salini JP, Blaber SJM, Brewer DT (1992) Diets of sharks from estuaries and adjacent waters of the north-eastern Gulf of

Editorial responsibility: Otto Kinne (Editor),

Oldendorf/Luhe, Germany
Carpentaria, Australia. Aust J Mar Freshw Res 43:87-96

Schmid TH, Murru FL, McDonald F (1990) Feeding habits and growth rates of bull (Carcharhinus leucas (Valenciennes)), sandbar (Carcharhinus plumbeus (Nardol), sandtiger (Eugomphodus taurus (Rafinesque)), and nurse (Ginglymostoma cirratum (Bonnaterre)) sharks maintained in captivity. J Aquaric Aquat Sci V(4):100-105

Smith RL, Salini JP, Blaber SJM (1991) Food intake and growth in the Moses Perch, Lutjanus russelli (Bleeker). with reference to predation on penaeid prawns. J Fish Biol 38:897-903

Smith RL, Salini JP, Blaber SJM (1992) Food intake and growth in the Blue-spotted Trevally, Caranx bucculentus Alleyne and Macleay 1877, with reference to predation. on penaeid prawns. J Fish Biol 40:315-324

Stillwell CE, Kohler NE (1993) Food of the sandbar shark Carcharhinus plumbeus off the U.S. nor theast coast, with estimates of dally ration. Fish Bull US 91:138-150

Wetherbee BM, Gruber SH (1990) The effects of ration level on food retention time in juvenile lemon sharks, Negaprion brevirostris. Environ Biol Fishes 29:59-65

Wetherbee BM, Gruber SH (1993) Absorption efficiency of the lemon shark Negaprion brevirostris at varying rates of energy intake. Copeia 1993(2):416-425

Wetherbee BM, Gruber SH, Cortés E (1990) Diet, feeding habits, digestion and consumption in sharks, with special reference to the lemon shark, Negaprion brevirostris. In: Pratt HL Jr, Gruber SH, Taniuchi T (eds) Elasmobranchs as living resources: advances in the biology, ecology, systematics and the status of the fisheries. US Dep Commer, Seattle, NOAA. Tech Rep NMFS 90, p 29-47

Submitted: September 21, 1998; Accepted: March 2, 1999

Proofs received from author(s): July 6, 1999 